\title{
Lifestyle factors and the metabolic syndrome in Schizophrenia: a cross-sectional study
}

\author{
Adrian Heald ${ }^{1,2}$, John Pendlebury 3 , Simon Anderson ${ }^{4}$, Vinesh Narayan³, Mark Guy ${ }^{5}$, Martin Gibson², \\ Peter Haddad $^{3}$ and Mark Livingston ${ }^{6^{*}}$
}

\begin{abstract}
Background: Cardiometabolic disease is more common in patients with schizophrenia than the general population. Aim: The purpose of the study was to assess lifestyle factors, including diet and exercise, in patients with schizophrenia and estimate the prevalence of metabolic syndrome.

Methods: This is a cross-sectional study of a representative group of outpatients with schizophrenia in Salford, UK. An interview supplemented by questionnaires was used to assess diet, physical activity, and cigarette and alcohol use. Likert scales assessed subjects' views of diet and activity. A physical examination and relevant blood tests were conducted.
\end{abstract}

Results: Thirty-seven people were included in the study. $92 \%$ of men had central adiposity, as did $91.7 \%$ of women (International Diabetes Federation Definition). The mean age was 46.2 years and mean illness duration was 11.6 years. $67.6 \%$ fulfilled criteria for the metabolic syndrome. The mean number of fruit and vegetable portions per day was $2.8 \pm 1.8$. Over a third did not eat any fruit in a typical week. $42 \%$ reported doing no vigorous activity in a typical week. 64.9\% smoked and in many cigarette use was heavy. The Likert scale showed that a high proportion of patients had insight into their unhealthy lifestyles.

Conclusions: Within this sample, there was a high prevalence of poor diet, smoking and inadequate exercise. Many did not follow national recommendations for dietary intake of fruit and vegetables and daily exercise. These factors probably contribute to the high prevalence of metabolic syndrome. Many had insight into their unhealthy lifestyles. Thus, there is potential for interventions to improve lifestyle factors and reduce the risk of cardiometabolic disease.

Keywords: Diet, Lifestyle, Schizophrenia, Metabolic syndrome

\section{Background}

People with schizophrenia suffer from increased morbidity and mortality compared with the general population, having a life expectancy that is approximately $20 \%$ shorter [1]. The excess mortality is largely due to cardiovascular disease (CVD). Furthermore, people with schizophrenia and other severe and enduring mental illnesses (SMI) are twice as likely to die from CVD compared with

\footnotetext{
*Correspondence: mark.livingston@nhs.net

${ }^{6}$ Department of Blood Sciences, Walsall Manor Hospital,

Walsall WS2 9PS, UK

Full list of author information is available at the end of the article
}

those in the general population [2-4], and the excess mortality is higher in younger individuals. Known risk factors for CVD include smoking, being overweight, inadequate exercise and a low intake of fruit and vegetables [5]. These lifestyle risk factors are more common in people with schizophrenia than in the general population [6-9].

In a North-American review, $42 \%$ of individuals with schizophrenia were reported to be obese [body mass index $(\mathrm{BMI}) \geq 27 \mathrm{~kg} / \mathrm{m}^{2}$ ] compared with $27 \%$ of the general population [6]. McCreadie and colleagues [7, 8] showed that the diets of people with schizophrenia in Scotland were less healthy than those of the general 
population on a range of parameters. Short-term efforts to improve diet in individuals with schizophrenia have been shown to be of only limited benefit [10] with the implication that any intervention must be long-term to be effective. Studies have repeatedly reported high rates of smoking in those with schizophrenia [8]. Information about exercise levels in schizophrenia is scanty, but clinical experience suggests it is often poor.

The high prevalence of poor diet, inadequate exercise and obesity in schizophrenia may partly reflect the associated socio-economic disadvantages of the illness, and many sufferers are unable to gain paid employment. In addition, core psychiatric symptoms including avolition and tiredness may contribute. Antipsychotic medication can cause metabolic derangements, including hyperglycemia and hyperlipidaemia [11,12] as well as weight gain $[12,13]$ which if sustained can contribute to CVD. Other psychiatric medications, including mood stabilisers and some antidepressants, can also cause weight gain [2]. In summary, the excess of CVD in schizophrenia appears multifactorial.

Given the evidence of suboptimal lifestyle choices in people with SMI, the aims of this study were to determine the pattern of dietary intake and exercise in a representative group of individuals with schizophrenia in a UK inner city area and to determine whether age predicted the presence of metabolic syndrome in this group.

\section{Methods}

The study was carried out at two Community Mental Health Centres in Salford, an inner city area in North West England, UK. The study was approved by the local Salford Ethics Committee and the Trust Research and Development Department. All outpatients aged between 16 and 65 years of age who were prescribed a neuroleptic drug and had a diagnosis of schizophrenia or schizoaffective disorder were eligible to enter the study. A series of consecutive outpatients were asked to consider entering the study. The majority of participants (23 out of 37 ) were living alone.

With regard to the characteristics of responders vs non-responders, in relation to clinical variables, for those non-responders for whom data are available ( 21 service users), there was no significant difference in age, BMI, blood glucose, and cholesterol level between the groups.

Patients who consented attended for a single assessment in a fasted state (i.e. not having had anything to eat since $22.00 \mathrm{~h}$ the night before). They completed a short interview to assess diet and activity in the previous week (Additional file 1). Assessment of diet and exercise was based on validated assessment tools [14]. Activity was rated as vigorous or moderate using the definitions given in Additional file 1. Subjects also completed Likert scales (rated 1-10) that assessed their views of diet, activity and medication compliance.

Each participant underwent basic anthropometric measurements, namely height, weight, and waist: hip ratio. Pulse and blood pressure were checked using a validated semi-automatic Omron HEM-705CP monitor (Omron Healthcare, Kyoto, Japan). The interviews and anthropometric measurements were undertaken by one of two trained research nurses. Socio-demographic details, details of psychiatric and medical history, and current prescribed medication were taken from the medical notes.

A fasting blood sample was taken for a variety of biochemical tests including serum glucose, lipids and prolactin. Apart from prolactin measurement, all assays were performed on the Roche Modular System (Burgess Hill, West Sussex, UK). Prolactin was assayed on the Siemens Immulite 2000 automated analyser (Siemens Healthcare Diagnostics, Frimley, Camberley, Surrey, UK).

\section{Metabolic syndrome definition}

According to the 2005 IDF definition [15], for a person to be defined as having the metabolic syndrome they must have the following:

Central obesity (defined as waist circumference $\geq 94 \mathrm{~cm}$ for European men and $\geq 80 \mathrm{~cm}$ for European women, with ethnicity specific values for other groups, specifically $90 \mathrm{~cm}$ for South Asian and Oriental origin men) plus any two of the following four factors (all but two of the participants in this study were of European origin):

- raised TG level: $\geq 150 \mathrm{mg} / \mathrm{dL}$ (1.7 mmol/L), or specific treatment for this lipid abnormality

- reduced HDL cholesterol: $<40 \mathrm{mg} / \mathrm{dL}(1.03 \mathrm{mmol} / \mathrm{L})$ in males and $<50 \mathrm{mg} / \mathrm{dL}(1.29 \mathrm{mmol} / \mathrm{L})$ in females, or specific treatment for this lipid abnormality

- raised blood pressure: systolic BP $\geq 130$ or diastolic $\mathrm{BP} \geq 85 \mathrm{mmHg}$, or treatment of previously diagnosed hypertension

- raised fasting plasma glucose (FPG) $\geq 100 \mathrm{mg} / \mathrm{dL}$ (5.6 $\mathrm{mmol} / \mathrm{L}$ ), or previously diagnosed type 2 diabetes if $>5.6 \mathrm{mmol} / \mathrm{L}$ or $100 \mathrm{mg} / \mathrm{dL}$.

\section{Results}

\section{Sample characteristics}

The response rate among those eligible to enter the study was $41 \%$. Twenty-five men and twelve women participated in the study. All had schizophrenia or schizoaffective disorder.

The mean duration of illness was 11.6 years ( $95 \%$ confidence interval: 7.3-18.2). The mean age was 46.2 years (46.2-49.2). Of the group, 30 (81\%) were unemployed, 
four were in paid employment, one was in voluntary employment, one was retired, and one was off work due to sickness at the time of interview. The majority of participants (35 out of 37) were of White European origin, with one of South Asian ethnicity, and one of Chinese ethnicity. In keeping with the protocol, all patients were taking neuroleptic medication. The key results are summarised in Table 1.

Of the participants, 20 out of 37 were taking oral atypical agents (eight were taking Clozapine) with 13 on depot neuroleptics (of which two were receiving depot Risperidone) and four on mood stabilisers as the primary psychotropic agent.

\section{Smoking and alcohol use}

Twenty-four out of 37 subjects (64.9\%) were current smokers, six (16.2\%) were ex-smokers with seven (18.9\%) never having smoked. Of the current smokers, four smoked between 1 and 10 cigarettes per day, nine between 11 and 20 cigarettes per day, and eleven between 21 and 60 cigarettes per day. $15 \%$ of male subjects consumed above the recommended safe levels of alcohol in a week (21 units per week). No women consumed above the recommended safe levels of alcohol in a week (14

Table 1 Details of sample and key results

\begin{tabular}{|c|c|}
\hline Socio-demographic factors & $\begin{array}{l}\text { Number and \% of patients } \\
\text { (unless otherwise specified) }\end{array}$ \\
\hline Mean age $(95 \% \mathrm{Cl})$, yrs & $46.2(43.2-49.2)$ \\
\hline Male (\%) & $25(67.6)$ \\
\hline Mean duration of illness $(95 \% \mathrm{Cl})$, yrs & $11.6(7.3-18.2)$ \\
\hline Caucasian (\%) & $35(94.6)$ \\
\hline \multicolumn{2}{|l|}{ Lifestyle parameters } \\
\hline $\begin{array}{l}5 \text { portions or more of fruit and vegeta- } \\
\text { bles per day (\%) }\end{array}$ & 13.5 \\
\hline Fresh fruit at least once a week (\%) & 62.5 \\
\hline $\begin{array}{l}\text { Vigorous exercise taken once a week } \\
\text { for } \geq 10 \mathrm{~min}(\%)\end{array}$ & 29 \\
\hline $\mathrm{BMI} \geq 30(\%)$ & 47.2 \\
\hline Current smoker (\%) & 64.9 \\
\hline Weekly alcohol > safe limits (\%) & 15 \\
\hline \multicolumn{2}{|l|}{ Blood parameters } \\
\hline $\begin{array}{l}\text { Fasting glucose elevated }>6.0 \mathrm{mmol} / \mathrm{L} \\
(\%)\end{array}$ & 21.2 \\
\hline Cholesterol >5 mmol/L (\%) & 48 \\
\hline Prolactin elevated >1000 mu/L (\%) & 16.7 \\
\hline \multicolumn{2}{|l|}{ Miscellaneous } \\
\hline Blood pressure > 140/90 mmHg (\%) & 32.4 \\
\hline Metabolic syndrome (\%) & 67.6 \\
\hline Regard diet as unhealthy (\%) & 54.1 \\
\hline $\begin{array}{l}\text { Regard themselves as physically inactive } \\
\text { (\%) }\end{array}$ & 51.4 \\
\hline
\end{tabular}

units per week). Of the total sample of 37 patients, 14 took no alcohol in a week.

\section{Weight and related measurements}

Within the group, BMI ranged from 18.4 to $52.4 \mathrm{~kg} / \mathrm{m}^{2}$ (normal range: $18.5-25.0 \mathrm{~kg} / \mathrm{m}^{2}$; World Health Organisation [16]). Mean (95\% CI) BMI for men was 31.2 $(28.2-34.3) \mathrm{kg} / \mathrm{m}^{2}$, and for women was $31.8(26.3-37.3)$ $\mathrm{kg} / \mathrm{m}^{2} .47 .2 \%$ of the group had a BMI in the obese range $\left(\geq 30.0 \mathrm{~kg} / \mathrm{m}^{2}\right)$. Thirty-two (86.5\%) reported that they did not find it difficult to put on weight.

For men (all of White European origin), mean (95\% CI) waist circumference was 106.9 (100.8-112.9) cm (Fig. 1). For Caucasian men, central adiposity is defined as waist $\geq 94 \mathrm{~cm}$ [15]. For men (one was South Asian), waist circumference was $96.5(86.7-106.3) \mathrm{cm}$ (Fig. 1). For women of European and South Asian ethnicity, central adiposity is defined as waist $\geq 80 \mathrm{~cm}$ [16]. $92.0 \%$ of men had central adiposity as defined, as did $91.7 \%$ of women.

\section{Pulse and blood pressure}

Mean $( \pm$ SD) systolic blood pressure was $126 \pm 19 \mathrm{mmHg}$ and mean diastolic blood pressure was $80 \pm 13 \mathrm{mmHg}$. $21.6 \%$ had a systolic blood pressure $>140 \mathrm{mmHg}$ and $45.9 \%$ a diastolic blood pressure $>80 \mathrm{mmHg}$.

\section{Laboratory results}

Four out of 37 patients were known to have diabetes, and three of the 37 patients $(8.1 \%)$ had a fasting glucose between 6.1 and $6.9 \mathrm{mmol} / \mathrm{L}$ [17]. Fasting total cholesterol was $>5 \mathrm{mmol} / \mathrm{L}$ in $48 \%$ of individuals with fasting LDL-cholesterol $>3 \mathrm{mmol} / \mathrm{L}$ in $43.3 \%$ of patients. $16.7 \%$ of the patients had a serum prolactin $>1000 \mu \mathrm{L}$, the threshold agreed by local endocrine services as meriting further investigation.

\section{Metabolic syndrome}

Twenty-five patients (67.6\%) would be categorised as having the metabolic syndrome using the International Diabetes Federation (IDF) Criteria [15]. This was more likely if the individual was older (odds ratio 1.4 (95\% CI $1.32-1.48)$.

\section{Diet}

Thirty-two participants completed the dietary questionnaire. A total of $13.5 \%$ of participants ate $\geq 5$ portions of fruit and vegetables per day. Mean $( \pm \mathrm{SD})$ portions of fruit per day were $1.1 \pm 1.0$ and of vegetables were $1.7 \pm 1.2$. Total fruit and vegetable portions were $2.8 \pm 1.8$. For the group, oily fish was eaten on average on $0.5 \pm 0.6$ days of each week.

Fruit was only eaten on $\geq 3$ days each week by $34.4 \%$ of the group, with $37.5 \%$ reporting not eating fruit on 


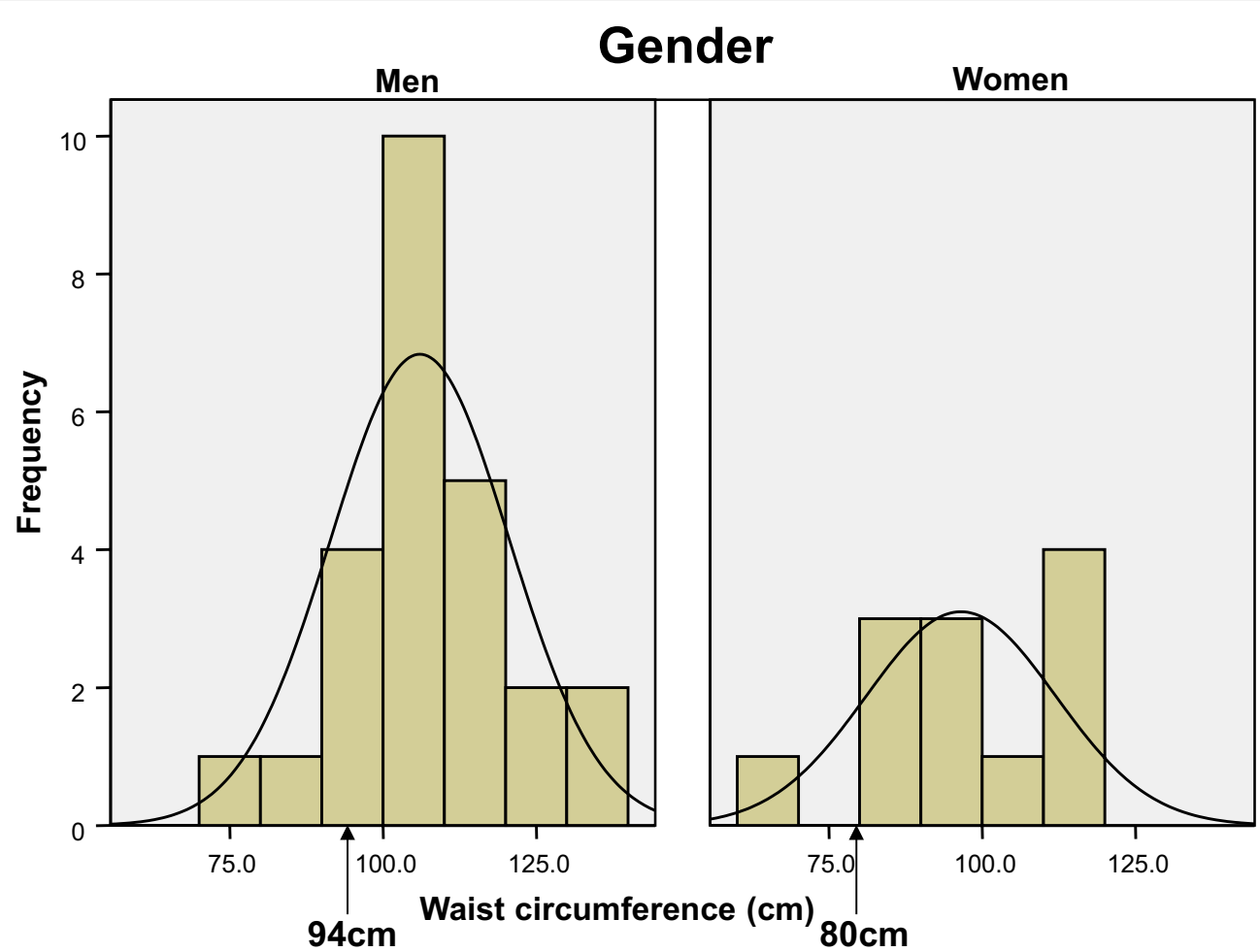

Fig. 1 Distribution of waist circumference for men and women. The 80 and 94-cm marks on the figure indicate the cut points for the International Diabetes Federation [15] definition of central adiposity

any day of the week (Table 2). Vegetables were eaten on $\geq 3$ days of each week by $59.4 \%$ of individuals.

With regard to takeaway foods, twelve (37.5\%) did not have any in the previous week, 18 (56.3\%) had 1-2 takeaways and two $(6.3 \%)$ had $>2$ takeaways. For ready meals, the breakdown was similar with $50 \%$ (16 out of 32 ) having none, $34.4 \%(11 / 32)$ having $1-2$ ready meals, $9.4 \%$ (3 out of 32 ) having $3-4$ ready meals but $6.3 \%$ (2 out of 32 ) having $\geq 7$.

For crisps, 18 out of 32 (56.3\%) had no crisps in the last week and for bread $56.3 \%$ (18 out of 32 ) had white bread, 13 wholemeal/granary bread/brown bread, and one had no bread.

Table 2 Breakdown of fruit and vegetable intake in a week for the whole group

\begin{tabular}{llll}
\hline $\begin{array}{l}\text { Number of days } \\
\text { eating vegetables }\end{array}$ & \% of group & $\begin{array}{l}\text { Number of days } \\
\text { eating fruit }\end{array}$ & \% of group \\
\hline 0 & 12.5 & 0 & 37.5 \\
$1-2$ & 28.1 & $1-2$ & 28.1 \\
$3-5$ & 34.4 & $3-5$ & 18.8 \\
$>5$ & 25.0 & $>5$ & 15.6 \\
\hline
\end{tabular}

\section{Activity}

$41.9 \%$ of participants reported doing no vigorous activity in the last week (see Additional file 1 for definition). $35.5 \%$ did $<1 \mathrm{~h}$ of vigorous activity per week. Only $29 \%$ did $\geq 10$ min of vigorous activity per week. $29 \%$ described doing no moderate activity in any week and 39\% of patients did so for $<1 \mathrm{~h}$ per week (Fig. 2). Of 31 responders, 21 walked for $<1 \mathrm{~h}$ each day, 14 said that they walked for $\geq 10$ min each day with five walking once or not at all in any week, and the remaining twelve walking 2-6 times each week for $>10 \mathrm{~min}$.

\section{Likert scale ratings}

The people studied displayed an understanding that their lifestyle was less healthy than might be achieved, in terms of both diet and exercise.

\section{Diet}

Patient ratings on a visual scale of 1-10 for the question 'Would you describe your diet as healthy (average over the last 3 months)?' gave a mean \pm SD of $5.7 \pm 2.2$. The anchor points were $0=$ very unhealthy, $10=$ very healthy. 


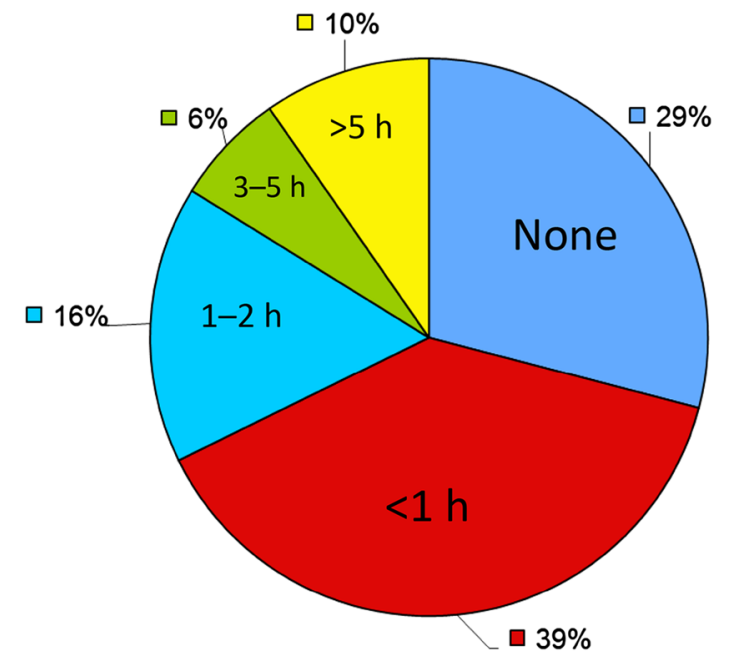

Fig. 2 Moderate exercise activities (hours per week) in a typical week

\section{Activity}

Patient ratings on a visual scale of 1-10 for the question 'Would you consider yourself fairly physically active (average over the last 3 months)? gave a mean \pm SD of $5.0 \pm 2.9$. The anchor points were $0=$ very physically inactive, $10=$ very physically active.

\section{Medication compliance}

Patient ratings on a visual scale of 1-10 for the question 'Are you compliant with medication prescribed for you to take (over the last 3 months)?' gave a mean \pm SD of $9.8 \pm 0.8$. The anchor points were $0=$ not compliant, $10=$ very compliant.

If a score of $<5.0$ on the Likert scales is used to indicate that a patient does not think they have a healthy diet, and a score $<5.0$ as a patient regarding themselves as not physically active, then the percentage of patients who accepted that they had a problem in these two areas was 54.1 and $51.4 \%$, respectively.

\section{Discussion}

We report three important findings from this study: (i) a high prevalence of metabolic syndrome; (ii) a high prevalence of poor diet, smoking and inadequate exercise; and (iii) that a high proportion of patients have insight into their unhealthy lifestyles. In relation to the third finding, we believe that an insight into lifestyle has not previously been reported. The fact that our subjects showed some degree of insight into their lifestyle problems indicates that there is potential for working with this group to improve the quality of diet and to increase the amount of exercise taken each day $[10,18]$.
In terms of methodology, the study sample was small but it is representative of patients with schizophrenia and schizoaffective disorder. In the current study, we approached a consecutive series of outpatients and just over $40 \%$ took part in the study. This is comparable with contemporary analysis of rates of screening in UK Primary Care [19].

If there is a sampling bias, it is likely that more motivated patients with healthier lifestyles took part. Patients were asked to attend in a fasted state and this was checked with them on the day that they attended. All anthropometric measurements were taken by one of two trained research nurses ensuring accuracy and consistency. The cut-offs that were used to define insight into lifestyle on the Likert scales have not been formally assessed; however, assessment of diet and exercise was based on validated assessment tools [14].

The prevalence of metabolic syndrome in our group was $67.6 \%$. This is a major concern because metabolic syndrome is a strong predictor of CVD [15, 19, 20] and of cardiovascular death [21]. The rates of metabolic syndrome are similar to other studies. In terms of components of the metabolic syndrome, most patients had a BMI and waist circumference above normal thresholds, with $92 \%$ of both men and women having central adiposity. Perhaps surprisingly, only a fifth of patients had an elevated systolic blood pressure.

Many individuals did not follow the recommendations for dietary intake of fruit and vegetables [22]. A significant proportion did not exercise as much as is recommended [17]. Levels of smoking were high. These results mirrored the seminal work done on lifestyle in schizophrenia conducted by McCreadie et al. [7] in the 1990 s and subsequently $[8,9]$. It is of concern that there has been no improvement in the intervening period. In particular, the last decade has seen investment in strategies to reduce smoking in the general population which have been successful. In contrast, smoking levels remain high in those with SMI. Our data show that the problems noted by McCreadie [8] in a Scottish sample, namely high levels of smoking, poor diet and low levels of exercise are also seen in England, increasing the likelihood that these findings represent the national picture.

Regular health screening, including measurement of fasting lipids and glucose, is recommended for those with SMI and those treated with antipsychotics in many treatment guidelines [23]. In addition, it is generally agreed that lifestyle interventions are necessary to improve physical health of SMI patients [24, 25]. In non-psychiatric patients at high risk of developing diabetes, simple lifestyle adjustments have been shown to reduce diabetes risk. These interventions include decreasing calorific and fat content of food and increase fibre intake, increasing 
intake of fruit and vegetables, eating complex rather than simple carbohydrates (e.g. whole-wheat bread rather than refined white bread) and avoiding sugary drinks, as well as carrying out exercise for at least 10-15 min per day. Advice to the general population to improve fruit and vegetable intake has been shown to be successful, at least in the short term [26].

In an intervention study [9], the diet of people with schizophrenia improved when they were given free fruit and vegetables; however, this was not sustained after withdrawal of the intervention, although there was a trend for the return to pre-intervention consumption to be more gradual when the free food intervention was combined with dietary advice.

A significant proportion of patients in our study had hyperprolactinaemia. This is a recognised adverse effect of many antipsychotics $[27,28]$. The propensity to cause hyperprolactinaemia varies significantly between different atypical antipsychotics. Raised prolactin can be asymptomatic, leading to various acute adverse effects, and can also result in long-term medical problems, including osteoporosis.

We do not have a direct comparison group from the general population. However, a detailed survey of the Salford UK population in terms of lifestyle is underway (www.citizenscientist.org.uk). The majority of the participants were living alone, so collection from someone cohabiting with them was not possible.

It could be argued that the quality of diet found in our study group is not significantly different from that of people in a similar socio-demographic situation [29]. However, the high rates of diabetes and cardiovascular events [2-4] in SMI define them as a high-risk group for cardiometabolic disease and, as such, there is the potential for targeted intervention to produce benefit.

We recommend the following principles of management to reduce cardiometabolic risk:

- Potential pre-diabetes states should be investigated and managed as per agreed guidelines for the general population but with annual screening for this recommended for those with psychosis receiving antipsychotic medications. The prescription of metformin for those not responding to or not adherent to intensive lifestyle interventions needs to be considered in the context of the individual service user.

- Diabetes should be managed by the family practitioner or a specialist physician where necessary.

- Dyslipidemia, especially in the context of a patient with diabetes, should be actively managed according to existing guidelines for the general population. There is no contra-indication to the prescription of a statin.
- Hypertension should be managed according to national guidelines. There is no contra-indication to prescription of antihypertensive medications.

- Smoking is an important additive risk factor for diabetes and cardiovascular disease and service users who smoke should be referred to smoking cessation services.

Our data show that there is scope to achieve a more healthy lifestyle in individuals with SMI. Such improvements require collaboration between local Mental Health providers and General practitioners plus specialist services, particularly dietetics, community health trainers and occupational therapy. It is likely that in many areas of the UK, and elsewhere, significant healthcare system redesign will be necessary to achieve this goal [30].

One of the founding principles of the NHS in 1948 was that it should strive to improve the health of the individual and the population and prevent disease. The needs of the service users lie at the heart of this fundamental mission and of other healthcare providers across the world responsible for the welfare of patients with schizophrenia and other forms of severe enduring illness.

\section{Conclusions}

Within this sample, there was a high prevalence of poor diet, smoking and inadequate exercise. Many did not follow national recommendations for dietary intake of fruit and vegetables and daily exercise. These factors probably contribute to the high prevalence of metabolic syndrome. Many had insight into their unhealthy lifestyles. Thus, there is potential for interventions to improve lifestyle factors and reduce the risk of cardiometabolic disease.

\section{Additional file}

Additional file 1. Comparison of absorption of dietary macronutrients and biochemical markers related to obesity in a population at the extremes of weight distribution.

\section{Abbreviations \\ BMI: body mass index; CVD: cardiovascular disease; FBG: fasting blood glucose; IDF: International Diabetes Federation; SMI: severe and enduring mental illnesses.}

\section{Authors' contributions}

$\mathrm{AHH}$ and $\mathrm{PH}$ conceived the project. $\mathrm{AHH}, \mathrm{PH}$ and $\mathrm{ML}$ were principal contributors to writing the manuscript. JP and VN recruited patients and assisted in the composition of the manuscript. MG performed the laboratory analyses. SGA carried out the statistical analysis. All authors read and approved the final manuscript.

\section{Author details}

1 Department of Medicine, Leighton Hospital, Crewe CW1 4QJ, Cheshire, UK. ${ }^{2}$ The School of Medicine and Manchester Academic Health Sciences Centre, University of Manchester, Manchester M13 9PT, UK. ${ }^{3}$ Greater Manchester West Mental Health NHS Foundation Trust, Greater Manchester, UK. ${ }^{4}$ Institute 
of Cardiovascular Sciences, University of Manchester, Manchester, UK. ${ }^{5}$ Department of Clinical Biochemistry, Salford Royal Hospital, Salford M6 8HD, UK. ${ }^{6}$ Department of Blood Sciences, Walsall Manor Hospital, Walsall WS2 9PS, UK.

\section{Acknowledgements}

None.

\section{Competing interests}

The authors declare that they have no competing interests.

\section{Ethical approval}

Full Ethics approval for the Study was given by the Salford Ethics Committee. All participants had given informed consent to be included in the study. All authors of the paper consent to publication of this paper. The data and other materials will be provided on request by the corresponding author.

\section{Ethics, consent, permissions}

Informed consent was obtained.

\section{Human rights}

The manuscript does not report on or involve the use of any animal or human data or tissue. The manuscript does not contain any individual person's data.

Received: 20 November 2015 Accepted: 1 February 2017

Published online: 15 February 2017

\section{References}

1. Brown S. Excess mortality of schizophrenia. A meta-analysis. Br J Psychiatry. 1997; 171:502-8

2. Casey DE, Haupt DW, Newcomer JW, Henderson DC, Sernyak MJ, Davidson M, et al. Antipsychotic-induced weight gain and metabolic abnormalities: implications for increased mortality in patients with schizophrenia. J Clin Psychiatry. 2004;65(suppl 7):s4-18.

3. Casey DE. Metabolic issues and cardiovascular disease in patients with psychiatric disorders. Am J Med. 2005;118(suppl 2):s15-22.

4. Osborn DPJ, Levy G, Nazareth I, Petersen I, Islam A, King MB. Relative risk of cardiovascular and cancer mortality in people with severe mental illness from the United Kingdom's general practice research database. Arch Gen Psychiatry. 2007;64:242-9.

5. Gillman MW. Enjoy your fruits and vegetables. BMJ. 1996;313:765-6.

6. Allison DB, Fontaine KR, Heo M, Mentore JL, Cappelleri JC, Chandler LP, et al. The distribution of body mass index among individuals with and without schizophrenia. J Clin Psychiatry. 1999;60:215-20.

7. McCreadie R, Macdonald E, Blacklock C, Tilak-Singh D, Wiles D, Halliday J, et al. Dietary intake of schizophrenic patients in Nithsdale, Scotland: case control study. BMJ. 1998;317:784-5.

8. McCreadie RG. Diet, smoking and cardiovascular risk in people with schizophrenia: descriptive study. Br J Psychiatry. 2003;183:534-9.

9. Holt Rl, Abdelrahman T, Hirsch M, Dhesi Z, George T, Blincoe T, et al. The prevalence of undiagnosed metabolic abnormalities in people with serious mental illness. J Psychopharmacol. 2010;24:867-73.

10. McCreadie RG, Kelly C, Connolly M, Williams S, Baxter G, Lean M, et al. Dietary improvement in people with schizophrenia: randomised controlled trial. Br J Psychiatry. 2005;187:346-51.

11. Haddad PM, Sharma SG. Adverse effects of atypical antipsychotics: differential risk and clinical implications. CNS Drugs. 2007:21:911-36.

12. De Hert M, Correll CU, Bobes J, Cetkovich-Bakmas M, Cohen D, Asai I, et al. Physical illness in patients with severe mental disorders. I. Prevalence, impact of medications and disparities in health care. World Psychiatry. 2011;10:52-77.

13. Haddad P. Weight change with atypical antipsychotics in the treatment of schizophrenia. J Psychopharmacol. 2005;19(suppl):s16-27.
14. Heald AH, Sharma R, Anderson SG, Vyas A, Siddals K, Patel J, et al. Dietary intake and the IGF-system: effects of migration in two related populations in India and Britain with markedly different dietary intake. Public Health Nutr. 2005;8:620-7.

15. Alberti KG, Zimmet P, Shaw J. The metabolic syndrome-a new worldwide definition. Lancet. 2005;366:1059-62

16. World Health Organisation (WHO). Physical status: the use and interpretation of anthropometry. Report of a WHO Expert Committee. WHO. Technical Report Series 854. Geneva: World Health Organization; 1995.

17. World Health Organization: Definition, Diagnosis and Classification of Diabetes Mellitus and its Complications: Report of a WHO Consultation. Part 1: Diagnosis and Classification of Diabetes Mellitus. Geneva: World Health Organisation; 1999.

18. De Hert MA, Van Winkel R, Van Eyck D, Hanssens L, Wampers M, Scheen A, et al. Prevalence of the metabolic syndrome in patients with schizophrenia treated with antipsychotic medication. Schizophr Res. 2006;83:87-93.

19. Martin JL, Lowrie R, McConnachie A, McLean G, Mair F, Mercer SW, et al. Physical health indicators in major mental illness: analysis of QOF data across UK general practice. Br J Gen Pract. 2014;64:e649-56.

20. Heald AH, Montejo AL, Millar H, De Hert M, McCrae J, Correll CU. Management of physical health in patients with schizophrenia: practical recommendations. Eur Psychiatry. 2010;25:S41-5.

21. Galassi A, Reynolds K, He J. Metabolic syndrome and risk of cardiovascular disease: a meta-analysis. Am J Med. 2006;119:812-9.

22. Food Standards Agency (FSA). The balance of good health. London: FSA; 2001.

23. Taylor D, Paton C, Kerwin R. Maudsley prescribing guidelines. 9th ed. London: Informa Healthcare; 1997.

24. Bushe C, Haddad P, Peveler R, Pendlebury J. The role of lifestyle interventions and weight management in schizophrenia. J Psychopharmacol. 2005;19(6 suppl):s28-35.

25. Peet M. Diet, diabetes and schizophrenia: review and hypothesis. $\mathrm{Br} J$ Psychiatry. 2004;184(suppl. 47):s102-5.

26. Zino S, Skeaff M, Williams S, Mann J. Randomised controlled trial of effect of fruit vegetable consumption on plasma concentration and antioxidants. BMJ. 1997:314:1787-91.

27. Haddad PM, Wieck A. Antipsychotic-induced hyperprolactinaemia: mechanisms, clinical features and management. Drugs. 2004;64:2291-314.

28. Maguire GA. Prolactin elevation with antipsychotic medication: mechanism of action and clinical consequences. J Clin Psychiatry. 2002;63:56-62

29. Food Standards Agency (FSA). Low income diet and nutrition survey. London: FSA; 2001.

30. Bodenheimer T, Wagner $\mathrm{EH}$, Grumback K. Improving primary care for patients with chronic illness. JAMA. 2002;288:1775-9.

\section{Submit your next manuscript to BioMed Central and we will help you at every step:}

- We accept pre-submission inquiries

- Our selector tool helps you to find the most relevant journal

- We provide round the clock customer support

- Convenient online submission

- Thorough peer review

- Inclusion in PubMed and all major indexing services

- Maximum visibility for your research

Submit your manuscript at www.biomedcentral com/submit 